\title{
Ethical and psychological features of conflict prevention in interpersonal communication contacts
}

\author{
Vladimir Safianov ${ }^{1, *}$, Irina Sokolovskaya ${ }^{2}$, Olga Shcherbakova $^{3}$, Vitalij Belobragin ${ }^{4}$, and \\ Roman $\mathrm{Tkach}^{5}$ \\ ${ }^{1}$ Moscow Polytechnic University, Bolshaya Semyonovskaya Str, 38, 107023 Moscow, Russia \\ ${ }^{2}$ Russian State Social University, Wilhelm Pik Str., 4, p. 1, 129226 Moscow, Russia \\ ${ }^{3}$ Plekhanov Russian University of Economics, Yuzhnobutovskaya h.15. f. 24, 117042 Moscow, \\ Russia \\ ${ }^{4}$ Institute of Economics and culture, m. Semenovskaya ul. Ibragimova, 31, bldg. 1, 105318 Moscow, \\ Russia \\ ${ }^{5}$ Pacific National University, Karl Marx Street, 68, 680000 Khabarovsk, Russia
}

\begin{abstract}
It is difficult to overestimate the significance of conflict in business and personal contacts in all spheres of human existence. The ability to communicate without conflicts is quite highly regarded, and conflicting people always and everywhere cause negative impressions. As Descartes taught, before you talk about anything, you need to agree on terms. If we talk about interpersonal conflicts, it should be noted that conflicts grow out of contradictions and opposites, but they cannot be equated. The conflict situation is a pre-conflict phase. Conflicts are more terrible and more harmful than contradictions and conflict situations, as there is already a mutual infringement of the dignity of the parties to a conflict. Conflicts are always problems, tragedies, tears; it is an "evil foreign body" that interferes with healthy communication. That's why conflicts must be fought, that is why conflicts must be prevented. Conflicts, like diseases, are easier to prevent than to cure and resolve later. Given the foregoing, the problem of finding the most effective technologies for preventing interpersonal conflicts, conflict situations, and contradictions, as they say, means a lot, especially as it concerns conflicts in business and social organizations.
\end{abstract}

\section{Introduction}

First of all, to understand the problems of conflict prevention, it is necessary to comprehend the system of determination of the outbreak of conflicts. The diversity and breadth of conflict causes in communication are striking. A comprehensive analysis of the causes of conflict contacts in business and personal communication shows that all potential causes can be divided into three types.

The first type is the reasons associated with the contradictions of goals, values, meanings, value systems, that is, the reasons associated with axiological parameters.

\footnotetext{
*Corresponding author: intersputnik2018@gmail.com
} 
The second type is causes related to anthropological factors: gender, age, nationality, status, psychological type, occupation.

The third type is the reasons associated with the technique of communication, the norms, and rules of communication, etiquette.

These causes are only potential; they only become relevant when they are supplemented by their prime cause.

The prime cause of any communication conflict is the frustration of the dignity of at least one participant in this very contact. For example, if two partners have different, contradictory points of view on the same problem, it does not mean that there is a conflict between them.

The situation will become conflict only when at least one of the partners, for example, says: "What are you talking about is nonsense, forget about it and don't tell me about it again."

Instead of respecting the other person's point of view, the partner deprives a person of the right to have his/her point of view and does it in a rather categorical and uncultured manner. Such behavior can impinge upon the moral dignity of the partner and provide a basis for the escalation of the conflict situation.

To prevent conflict situations, we offer some moral and psychological principles, the knowledge and implementation of which can facilitate to form conflict-free communication skills.

There is a view that conflict-free communication is impossible and conflicts can be useful and constructive. It is based, in our opinion, on the substitution of two concepts contradiction and conflict (yes, indeed, there is no life without contradictions). However, the challenge is not to allow contradictions to escalate into conflicts. A culture of conflict-free contacts is still possible if we learn how to manage conflicts and if we master the science and art of preventing communicative conflicts.

Both psychological and ethical factors play an important role in conflict prevention. Some fundamentals can be defined as ethical-psychological principles of conflict prevention.

The authors note that among these principles one might call, first of all, the principles proposed by A. P. Eguides such as the principle of preservation of sovereignty and inviolability of subjects dignity, the principle of presumption of decency of a partner (that followed the legal principle of presumption of innocence), the principle of confidence, the principle of nonviolence, the principle of tolerance and altruism, the principle of mercy, the principle of "justice and generosity"[1].

These principles are expressed in general terms, and to be realized in the communicative process, they require concrete definitions, that manifest in the conflict genes and syntonic doctrine, which is essentially a more concrete, normative manifestation and expression of these principles.

Human dignity as a humanistic value of communication is related to his/her interests and needs: infringement of the communication partner's needs without the consent of him/her is detrimental to his/her moral dignity as well.

All those unpleasant elements of communication can frustrate the dignity of partners and, at least implicitly lead to a conflict situation in psychology, they are called conflict genes. (A.P. Eguides' term). And, on the contrary, all those elements of communication that respond to the needs of the subject and lead to the creation of a healthy moral-psychological atmosphere of communication, to the elevation of human dignity in practical psychology are called synthon (for the first time, in the $20^{\text {th }}$ century, the term "synthonia" was coined by the German psychologist E. Bleuler).

Syntons in psychology are called "psychological strokes" because they create the socalled "syntonia" - the consonance of emotional states of the subjects of communication.

Among the conflict genes, the most known are "signs of exclusion of the partner", negative evaluations, "signs of superiority", all-or-nothing mentality, back - word, ingratitude, accusations, laughter, "withholding information", obtrusion of advice on others", 
distrust, etc.

Among the syntons can be distinguished such as: " inclusiveness of a partner", compliments, active gratitude, self-blame, request to give advice, "publicity", self-humor, " promised and did faster and better than promised " etc.

The ethical principles of conflict prevention in communication, presented in specific syntons, are the basis for modeling special techniques, preventive methods that allow us to recognize a possible conflict in germ and to do everything possible to "extinguish" it as early as possible. The most important requirement that is the criterion for selecting possible methods of "conflict prevention techniques" is the ethical imperative to preserve the dignity of partners mutually.

The main way to achieve maximal conflict-free communication is the way to avoid evaluations or the way of maximal non-evaluation in communication. The principle of maximum non-evaluation in communication does not mean the total refusal of evaluation, it means the refusal of such negative and even positive evaluation, which can become conflict genes.

From the principles of conflict prevention, it is possible to move on to the implementation of norms and rules within the framework of practical interpersonal contacts. Thus the principle of the inviolability of moral dignity can be realized based on syntonic communication.

The attitudes toward various synthons and conflict genes are highly individual among all participants in communicative contacts. For this reason, the analysis of the anthropological characteristics of the participants in the conflict interaction is of great importance in the development of preventive technologies to tone down the conflict.

All attempts to develop strategies and tactics to prevent the processes of conflict, to give tips on preventing tone down the conflict, as a rule, end without positive results, if we could not find the "key" to influence the participants in the conflict.

To build a model of interpersonal conflict prevention it is simply necessary to refer to situational analysis, to psychological typologies of personality, because only this approach will allow implementation of individual models and projects of prevention, and perhaps resolution of conflict situations and conflicts. Among numerous psychological classifications of personality types for research and understanding of communicative contacts the classifications accentuation by K. Leonhard, A. E. Lichko, A. P. Eguides, E. Spirica are the most suitable.

These typologies of characters can allow the best way to implement an express diagnosis of the partner's character, determine his/her communicative features, to understand how works the "key" that will help to open the way to influence the possibilities of conflict-free contacts.

The priority in the research of the conflict problem belongs to foreign scientists-classics of various methodological directions (A. Adler, R. Dahrendorf, M. Deutsch, K. Levin, K. Thomas, 3. Freud, K. Horney, etc.) and modern foreign conflictologists (Campbell R.J., et al. [2]; Lioukas C. S., Reuer J. J. [3]; Jacquart P., Antonakis J. [4]; Schaubroeck J. M. et al. [5]; Kilduff G., Elfenbein H., Staw B. [6]; Pratt M. G., Rosa J. A. [7].

The problem of conflict has long been worked out in Russian psychology. In psychological works devoted to conflicts prevail the works on the general theory of conflicts (Dorofeev, D. Yu, \& Semenova, V.N.[8]; Kolevich Griffith, B.[9]; Abgazhava, D. A.[10]; Biricheva, E. V.[11]), on conflict research (Netsvetailova, E. N.[12]; Artemov, G.P., \& Pinkevich, A. G.[13]; Loginov, A. V, \& Rudenkin, D. V.[14]; Galustyan, H. S.[15]), the study of the structure, characteristics, and dynamics of conflicts (Shcherbakova O. I. et al[16]; Sokolovskaya I. E., Vasyakin B. S., Shcherbakova O. I.[17]), psychological characteristics of conflict personalities (Sokolovskaia I. E., Volochkov I. V.[18]; Khudoikina, T., \& Khalzova, R.[19]). 
At the same time, attention is drawn to the insufficient status of psychological bases, methods of prevention, and basic means of resolving conflicts in interpersonal communicative contacts.

\section{Materials and methods}

The problem of research was to find the most effective psychological technologies to form the cooperation in interpersonal communicative contacts in a conflict situation.

The object of the research was cooperation in interpersonal communicative contacts.

The subject is the psychological technologies that form the cooperation in interpersonal communicative contacts in a conflict situation.

The research aims to study the influence of psychological technologies on the formation of cooperation in interpersonal communication contacts in a conflict situation.

Research Hypothesis.

Theoretical hypothesis (main research hypothesis) is that psychological technologies help to form cooperation in interpersonal communicative contacts in a conflict situation.

Experimental hypothesis (EH) - application of psychological technologies in interpersonal communicative contacts reduces conflict and promotes the formation of cooperation.

Counter-hypothesis $(\mathrm{CH})$ - application of psychological technologies in interpersonal communicative contacts does not influence conflict and formation of cooperation.

H1 (difference hypothesis) - the level of cooperation in interpersonal communicative contacts before and after the use of psychological technologies will be different.

H0 (similarity hypothesis, null-hypothesis) - the level of cooperation in interpersonal communicative contacts before and after application of psychological techniques will not differ.

Research Methods:

1. Assessment technique of psychic atmosphere in a labor collective (by A.F. Fiedler).

2. Methodology "Definition of the group unity Sishor index".

3. K. Thomas's test "Strategies of behavior in a conflict".

4. Author's questionnaire "Cooperation in conflict situations".

Research base: "Inter-Sputnik" OOO (social and cultural center). 120 respondents aged 25-49 took part in the research.

\section{Results and discussion}

The research consisted of 3 stages: ascertaining, formative and test experiment.

The results of the ascertaining study of the psychic atmosphere and the level of the group unity in interpersonal communicative contacts (i. e. in the Center labor collective) were interpreted by us separately according to each technique. Let us analyze the obtained results.

1. Assessment technique of psychic atmosphere in a labor collective (by A.F. Fiedler). 
Table 1. The results of the assessment of psychic atmosphere in the labor collective at the ascertaining stage of the research.

\begin{tabular}{|c|c|c|c|c|c|c|}
\hline \multirow{2}{*}{ Scale } & \multicolumn{2}{|c|}{ High level } & \multicolumn{2}{c|}{ Average level } & \multicolumn{2}{c|}{ Low level } \\
\cline { 2 - 7 } & People. & $\%$ & People. & $\%$ & People. & $\%$ \\
\hline Friendliness / Hostility; & 43 & 36 & 51 & 42 & 26 & 22 \\
\hline Consent/Dissent; & 46 & 38 & 54 & 45 & 20 & 17 \\
\hline Satisfaction/Dissatisfaction; & 41 & 34 & 43 & 36 & 36 & 30 \\
\hline Productivity /Unproductivity; & 31 & 26 & 63 & 52 & 26 & 22 \\
\hline Warmth/ Coldness; & 40 & 33 & 54 & 45 & 26 & 22 \\
\hline Collaboration / Inconsistency; & 31 & 26 & 48 & 40 & 41 & 34 \\
\hline Mutual aid /Hostility; & 44 & 36 & 52 & 43 & 24 & 21 \\
\hline Enthusiasm / Indifference; & 36 & 30 & 61 & 51 & 23 & 19 \\
\hline Interest/ Boredom; & 34 & 28 & 72 & 60 & 14 & 12 \\
\hline Success / Lack of success & 40 & 33 & 53 & 44 & 27 & 23 \\
\hline
\end{tabular}

According to the data in Table 1, the processing data on quantitative indicators show that, according to $32 \%$ of the Center employees, there is a friendly psychic atmosphere in their collective. $46 \%$ of the respondents believe that their collective has a neutral psychic atmosphere, while $22 \%$ believe that the psychic atmosphere in the collective is negative.

The processing data on qualitative indicators show that, in general, the majority of respondents tend to believe that they have a neutral psychic atmosphere in the collective. In particular, the Center employees are satisfied with such characteristics of psychological climate as consent, mutual aid, and friendliness. But at the same time, there is inconsistency and lack of success, these characteristics do not allow the respondents to be satisfied with the psychic atmosphere in work.

2. Methodology «Definition of the group unity Sishor index".

Table 2. The results of the assessment of the group unity at the ascertaining stage of the research.

\begin{tabular}{|c|c|c|}
\hline \multirow{2}{*}{ The group unity level } & The experimental group (120 people) \\
\cline { 2 - 3 } & Number of people & $\%$ \\
\hline High & 22 & 18 \\
\hline Above average & 13 & 11 \\
\hline Average & 44 & 36 \\
\hline Below average & 28 & 24 \\
\hline Low level & 13 & 11 \\
\hline
\end{tabular}

To illustrate a point Fig. 1. 


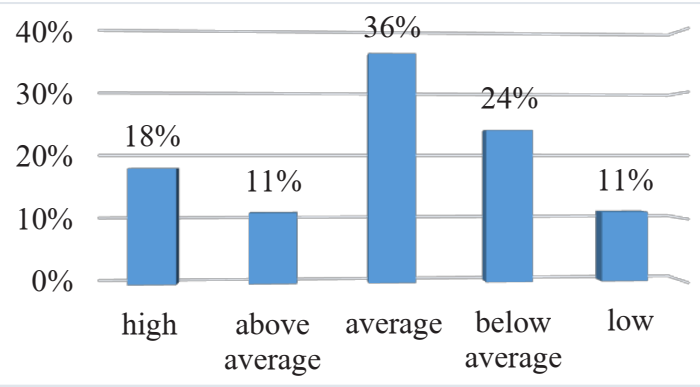

Fig. 1. The results of the assessment of the group unity at the ascertaining stage of the research.

The processing data on quantitative indicators show that $18 \%$ of respondents believe that their collective has a high level of group unity, 11\% - above average level, 36\% - average level. In turn, $24 \%$ of the Center employees believe that the level of group unity is below average, $11 \%$ - low level.

The processing data on qualitative indicators show that in general there is an average level of group unity. In particular, respondents feel community ownership, and would not want to switch to another group if they had such an opportunity. But at the same time, it is noted that the level of relations is not close enough and the attitude to work is worse than in other collectives.

3. K. Thomas's test "Strategies of behavior in a conflict

Table 3. Results of the assessment of strategies of the Center employees behavior in a conflict at the ascertaining stage of research.

\begin{tabular}{|c|c|c|}
\hline \multirow{2}{*}{ Strategy } & \multicolumn{2}{|c|}{ Dominant strategy } \\
\cline { 2 - 3 } & Number of people & $\%$ \\
\hline Rivalry & 32 & 27 \\
\hline Adaptation & 8 & 6 \\
\hline Compromise & 12 & 10 \\
\hline Avoidance & 63 & 52 \\
\hline Collaboration & 5 & 5 \\
\hline
\end{tabular}

To illustrate a point Fig. 2.

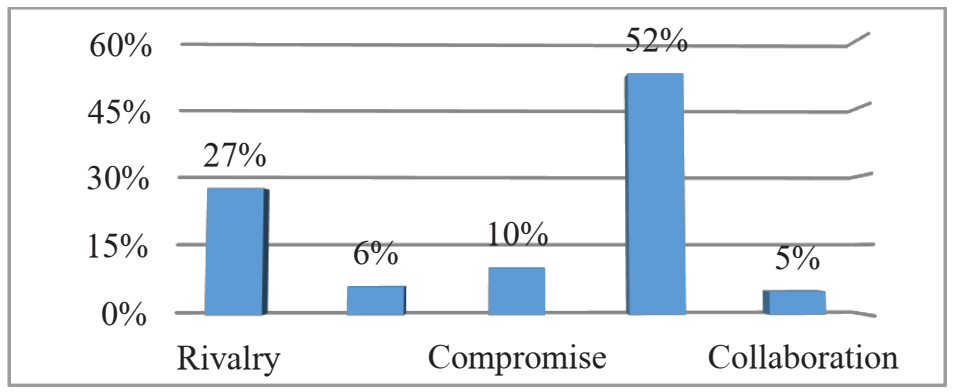

Fig. 2. Results of the assessment of strategies of the behavior of the Center employees in a conflict at the ascertaining stage of research. 
The processing data on quantitative indicators show that $52 \%$ of re-respondents in a conflict adhere to the strategy of avoidance, $27 \%$ - rivalry, $10 \%$ - compromise. In turn, $6 \%$ of the Center employees, respectively, the strategy of adaptation, $5 \%$ - collaboration.

The processing data on qualitative indicators show the majority of the Center employees in a conflict situation adhere to the avoidance strategy, which means sacrificing their interests for the sake of the other. In turn, the least number of respondents follow the strategy of collaboration, which means to search for an alternative that fully satisfies the interests of both parties.

4. Author's questionnaire "Cooperation in conflict situations".

Table 4. Results of the assessment of the development level of skills of cooperation in conflict situations at the ascertaining stage of the research.

\begin{tabular}{|c|c|c|}
\hline \multirow{2}{*}{$\begin{array}{c}\text { The group } \\
\text { unity level }\end{array}$} & $\begin{array}{c}|c| \\
\text { The experimental group (120 } \\
\text { people) }\end{array}$ \\
\cline { 2 - 3 } & Number of people & $\%$ \\
\hline High & 22 & 18 \\
\hline Average & 69 & 57 \\
\hline Low & 29 & 25 \\
\hline
\end{tabular}

To illustrate a point Fig. 3.

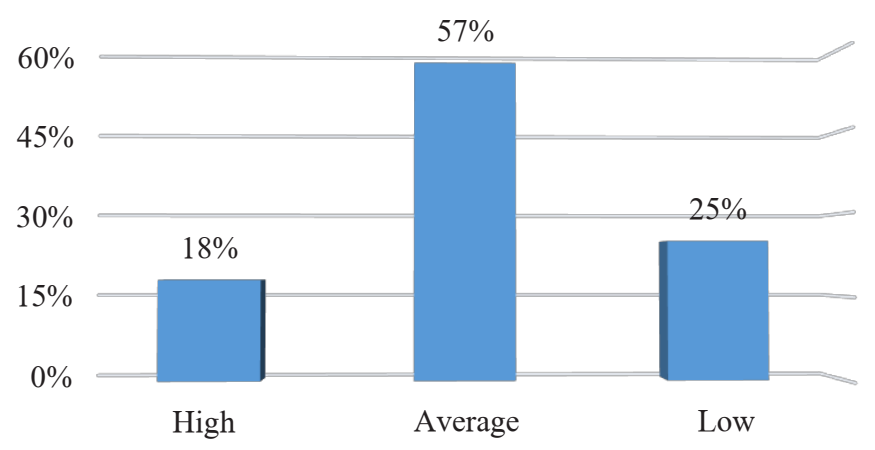

Fig. 3. Results of the assessment of the level of development of cooperation skills in conflict situations at the ascertaining stage of the study.

The processing data on quantitative indicators show that $18 \%$ of the Center employees have a high level of development of collaboration skills in conflict situations, $57 \%$ - average, and $25 \%$ - a low level of development of collaboration skills in conflict situations.

The processing data on qualitative indicators show the majority of respondents have the skills of collaboration in conflict situations on an average level. In particular, the Center employees try to understand the reason for the conflict, listen to the opponent and offer their way out of the conflict situation. But at the same time, they rarely discuss the problem, without disagreements and emotions, and quite often try to manipulate the opponent in conflict conditions.

To determine the relationship between the perception of psychic atmosphere, the group unity level, and the behavior features in the conflict of the Center employees, we conducted a correlation analysis of the data received. The results of the correlation analysis are in Table 5. 
Table 5. The results of the correlation analysis.

\begin{tabular}{|c|c|}
\hline Indicators & Correlation coefficient \\
\hline Psychic atmosphere - the group unity level & 0,49 \\
\hline $\begin{array}{c}\text { Psychic atmosphere - Level of development of } \\
\text { collaboration skills in conflict }\end{array}$ & 0,42 \\
\hline $\begin{array}{c}\text { The group unity level- Level of development } \\
\text { of collaboration skills in conflict }\end{array}$ & 0,84 \\
\hline
\end{tabular}

Let's analyze the results

1. There is a direct moderate correlation with the coefficient 0.49 between the level of psychic atmosphere in the collective and the group unity level. Consequently, the friendlier is the psychic atmosphere in the collective, the more cohesive are the respondents in their group.

2. There is a direct moderate correlation with the coefficient 0.42 between the level of psychic atmosphere in the collective and the level of development of collaboration skills in conflict. Consequently, the friendlier is the psychic atmosphere in the collective, the betterdeveloped skills of collaboration in the conflict they have.

3. There is a direct strong correlation with the coefficient 0,84 between the group unity level in the collective and the level of development of collaboration skills in conflict. Consequently, the higher the group unity level, the better the skills of collaboration in a conflict the Center employees have.

Based on these results, it was concluded that a direct strong correlation relationship is only between the group unity level and the level of development of collaboration skills in conflict $(\mathrm{R}=0.84)$.

In general, the analysis of the results of the ascertaining research led to the conclusion about the insufficient friendly psychic atmosphere, insufficient group unity level, and the level of development of skills of collaboration in the conflict in the Centre collective, which led to the conduct a formative stage of research.

Thus, based on the above, we can conclude that most respondents are inclined to believe that they have a neutral psychic atmosphere in the collective. In particular, the Center employees are most satisfied with such characteristics of the psychic atmosphere as consent, mutual aid, and friendliness. But at the same time, there is a lack of agreement and the lack of success, which do not allow respondents to be fully satisfied with the psychic atmosphere. It was also determined that the group unity level is average. In particular, respondents feel community ownership, and would not want to switch to another group if they had such an opportunity.

But at the same time, there is inconsistency and lack of success, these characteristics do not allow the respondents to be satisfied with the psychic atmosphere in work. The Analysis based on K. Thomas's test allowed us to conclude that most Center employees in a conflict situation adhere to the avoidance strategy that is to sacrifice one's interests for the sake of the other. In turn, the least number of respondents follow the strategy of collaboration, which is to search for an alternative that fully satisfies the interests of both parties. Finally, it was identified that the majority of respondents had an average level of collaboration skills in conflict situations. In particular, the Center employees try to understand the reason for the conflict, listen to the opponent and offer their way out of the conflict situation. But at the same time, they rarely discuss the problem, without disagreements and emotions, and quite often try to manipulate the opponent in conflict conditions. Based on the results of the correlation analysis, it was concluded that a direct strong correlation relationship is observed 
only between the group unity level and the level of development of collaboration skills in a conflict.

In general, the analysis of the results of the ascertaining research led to the conclusion about the insufficient friendly psychic atmosphere, insufficient group unity level, and the level of development of skills of collaboration in the conflict in the Centre collective, which led to conducting a formative stage of research. The analysis of the results led to the conclusion, that most respondents are inclined to the opinion that they have a neutral psychic atmosphere in the collective. There is inconsistency and lack of success, these characteristics do not allow the respondents to be satisfied with the psychic atmosphere in work. It was also determined that there is an average group unity level in the collective. The level of relationships in the collective is not close enough and the attitude to work is worse than in other collectives. The Analysis based on K. Thomas's test allowed us to conclude that most Center employees in a conflict situation adhere to the avoidance strategy that is to sacrifice one's interests for the sake of the other

Finally, it was identified that the majority of respondents had an average level of collaboration skills in conflict situations. In particular, respondents rarely discuss the problem, without disagreements and emotions, and quite often try to manipulate the opponent in conflict conditions.

During the formative stage of the research, we developed and tested a trial program to form a collaboration of the employees in a conflict situation. The trial program is geared to forming a friendly psychic atmosphere and raising the level of development of collaboration skills in a conflict situation.

The program of formative impacts was based on E. Bezrukov, I. Bukhtiyarov, Y. Sinyagin's theories, and others, within the framework of which 3 basic psychological techniques were chosen: the involvement of the Center employees in collaborative activities to strengthen tightly-welded tea and to organize psychological and educational work and individual psychological support of respondents to form collaboration skills in a conflict situation. The first implied monthly corporate events for team building. The annual plan of corporate events included corporate events in cafes, corporate games "What? Where? When?", team-building events, as well as environmental runs and camping. Psychological and educational work involved a series of events such as "Constructive strategies to overcome conflicts: compromise and collaboration"; role games " Conflict mitigation "; seminars " World without conflict. "; various exercises aimed at preventing conflicts in the collective ("Space Speed", "Interview", etc.), etc.

Finally, the organization of individual psychological follow-up for the Center employees implied: to conduct socio-psychological training programs to improve communication, assertive, creative skills and abilities; to teach various methods and techniques to overcome conflict; to provide psychological aid both individual and group counseling, and to open psychological counseling centers in a conflict situation.

\section{Conclusions}

According to the results of the follow-up study, it was found that the majority of respondents after the trial program began to perceive the psychic atmosphere in the collective as a friendly one. In particular, according to respondents, such characteristics of the group atmosphere as satisfaction with work-team relationships, collaboration and warmth have significantly improved. It was also found that after the end of the formative experiment, it was also determined that the group unity level is average. In particular, the respondents noted a significant improvement of relations between all participants of the collective and their attitude towards labor activity. At the control stage of the research, most of the Center employees began to align with collaboration strategy that is to search for an alternative that 
fully satisfies the interests of both parties. Finally, after the implementation of the follow-up study, the majority of respondents had a high level of development of collaboration skills in conflict situations. In particular, the Center employees learned to discuss the problem openly, without disagreements and emotions, and to accept the opinion of the opponent, if it helps to solve the conflict.

Based on the results of correlation analysis it was concluded that a direct strong correlation connection according to the results of the follow-up study was observed between the group unity level and the level of development of collaboration skills in the conflict $(\mathrm{R}=0,89)$, between the group unity level and psychic atmosphere $(\mathrm{R}=0,74)$ and between the development of collaboration skills in the conflict and psychic atmosphere $(\mathrm{R}=0,62)$. The student's t-test was calculated to determine statistical differences in the studied indicators among the Center employees at the ascertaining and follow-up stages of the research. According to the results, the differences in perception of psychic atmosphere, group unity level, and level of development of skills of collaboration in a conflict among the Center employees at the ascertaining and follow-up stages of research are statistically significant. Consequently, the effectiveness of the trial program to form the labor collaboration in a conflict situation was experimentally confirmed.

\section{References}

1. U. F. Sabirova, S. V. Gusenina, M. V. Sukhomlinova, V. I. Safyanov, International Journal of Innovative Technology and Exploring Engineering, 9(1), 3209 (2019)

2. R. J. Campbell, S.-H. Jeong, S. D. Graffin, Academy of Management Journal, 62(4), 1278 (2019)

3. C. S. Lioukas, J. J. Reuer, Academy of Management Journal, 58(6), 1826 (2015)

4. P. Jacquart, J. Antonakis, Academy of Management Journal, 58(4), 1051(2015)

5. J. M. Schaubroeck, S. T. Hannah, B. J. Avolio, S. W. J. Kozlowski, R. G. Lord, L. K. Treviño, N. Dimotakis, A. C. Peng, Academy of Management Journal, 55(5), 1053 (2012)

6. G. Kilduff, H. Elfenbein, B. Staw, Academy of Management Journal, 53(5), 943 (2010) http://web-docs.stern.nyu.edu

7. M. G. Pratt, J. A. Rosa, Academy of Management Journal, 46(4), 395 (2003)

8. D. Yu. Dorofeev, V. N. Semenova, Bulletin of Saint Petersburg University. Philosophy and Conflict Studies, 36(4), 687 (2020)

9. B. N. Griffith, Koljević, Bulletin of Saint Petersburg University. Philosophy and Conflict Studies, 36(4), 700 (2020)

10. D. A. Abgadzhava, Bulletin of Saint Petersburg University. Philosophy and Conflict Studies, 36(3), 511 (2020)

11. E. V. Biricheva, Bulletin of Saint Petersburg University. Philosophy and Conflict Studies, 35(4), 607 (2019)

12. E. N. Netsvetaylova, Scientific Almanac, 10-4(12), 405 (2015)

13. G. P. Artemov, A. G. Pinkevich, Bulletin of Saint Petersburg University. Philosophy and Conflict Studies, 36(3), 528 (2020)

14. A. V. Loginov, D. V. Rudenkin, Bulletin of Saint Petersburg University. Philosophy and Conflict Studies, 36(2), 341 (2020)

15. Kh. S. Galstyan, Bulletin of Saint Petersburg University. Philosophy and Conflict Studies, 35(4), 626 (2019) https://philosophyjournal.spbu.ru 
16. O. I. Shcherbakova, V. V. Velikorossov, V. O. Midova, D. K. Balakhanova, E. V. Genkin, A. V. Kolesnikov, A. K. Chernукh, O. G. Rakauskiene, International Journal of Applied Exercise Physiology, 9(12), 137 (2020)

17. I. E. Sokolovskaya, B. S. Vasyakin, O. I. Shcherbakova, Communicology, 7(2), 154 (2019)

18. I. E. Sokolovskaia, I. V. Volochkov, Cham, 155, 866 (2021) https://link.springer.com

19. T. Khudoikina, R. Khalzova, Bulletin of Science and Practice, 6(7), 307 (2020) https://www.archive-bulletennauki.com 